\title{
HYDRAULIC MODEL TESTS FOR INDIANA HARBOR DEVELOPMENT
}

\author{
Lorenz G. Straub \\ Consulting Engineer; Director, \\ St. Anthony Falls Hydraulic Laboratory, \\ Minneapolis, Minnesota
}

and

\author{
Robert Y. Hudson \\ Chief, Wave Action Section, Waterways Experiment Station, \\ Corps of Engineers, Department of the Army \\ Vicksburg, Mississippi
}

\section{INTRODUCTION}

Plant facilities of the Inland Steel Company, East Chicago, Indiana, and the East Chicago plant of the Youngstown Sheet and Tube Company, occupy the entire perimeter and adjacent shoreline of Indiana Harbor (Figs. 1, 2, and 3). Major changes in the plants of these companies required revisions in the shoreline and the building of various bulkheads within the harbor and in Lake Michigan outside the harbor breakwater. Small scale hydraulic model studies of the harbor and portions of certain harbor structures were conducted to aid in the solution in the wave action problems arisine from the construction programs of the two steel companies. Investigations concerned construction projects recently completed, projects under construction during the course of the model studies, and proposed future plans for plant expansion and harbor development.

Permits issued by the Federal Government for construction projects involving encroachments on lake areas and changes in harbor boundary conditions are sranted on the condition that such constructions do not adversely affect wave action and navigation conditions in and adjacent to the harbor. The primary purpose of the Indiana Harbor model (Figs. 2 and 3 ) was to determine the effects of present and future construction projects of the two steel companies on wave and navigation conditions and, where necessary, to devise modified designs which would satisfy permit requirements. Section models were also used to provide functional and economic design information on $s_{j}$ jecific aspects of certain of the structures, such as breakwater, bulkheads, and wave energy absorbers.

Hydraulic model investigations included (Fig. 3) studies of a 2500 $f t$ steel sheet pile cellular bulkhead (Project Area I) and a 33 acre pier expansion plan for the Younsstown Sheet and Tube Company (Project Area II), and a $5200^{\circ} \mathrm{ft}$ steel sheet pile cellular bulkhead (Project Area III), a $1200 \mathrm{ft}$ realignment of a dock (Project Area IV), and a 53 acre mooring area with adjacent docking facilities (Project Area V) for the Inland SteeI Company. Features of "Indiana Harbor as they existed before construction of the projects with which the model studies were concerned are show in Fig. 2. The currently projected and potential developments are indicated in Fig. 3; project areas I, III, and IV have been built. Typical breakwater sections are shown in Fig. 4. 


\section{COASTAL ENGINEERING}

Model studies were started in March, 1951, at the Waterways Experiment Station, a Laboratory of the Corps of Engineers, Department of the Army, located in Vicksburg, Mississippi. The studies of project areas I, III, IV, and V have been completed as of September, 1953; some further studies are to be made to establish optimum design for area II.

\section{GENERAL PROCEDURE OF THE MODEL STUDIES}

\section{PURPOSE OF THE INVESTIGATION}

The specific purpose of the model studies was to determine the effects on wave action and navigation conditions in the harbor 'and harbor approach area of construction in progress or planned by The Youngstown Sheet and Tube Company and the Inland Steel Company. The performing of model tests for all major harbor projects of the Corps of Engineers has been standard practlce for several years, and the advantages of conducting such studies have been proven many times. Thus, the use of small-scale hydraulic models to determine the effects of proposed plans on harbor conditions was a logical method of solving the problems which arose in planning for harbor and plant developments, while providing evidence that permit requirements were fulfilled. As the investigation progressed, the purpose and use of the models were enlarged to include the development of the most economical plans which would satisfy permit requirements, the providing of design information concerning wave forces on breakwaters and wave absorbers, and the economical development of future plans for which permits might be desired at a later date.

\section{TYPES OF MODELS USED IN THE INVESTTCATION}

In general there are two types of wave-action models. These are the harbor wave-action model and the wave-force or stability model. Harbor models usually reproduce the entire harbor area with the various shoreline stmuctures, and sufficient area seaward to allow proper generation and refraction of waves. Section models usually reproduce only a portion of a harbor or only a section of a harbor structure, such as a breakwater or wave absorber. Section models are used to determine the reflection, absorption, and stability characteristics of breakwaters, wave absorbers, and other harbor structures, as a function of wave height, wave length, and wave direction.

Both types of models were used in the Indiana Harbor investigation. The harbor model was constructed of concrete to a linear scale of $1: 150$, model to prototype. The section models had linear scales of 1:50 and 1:55.

\section{DESIGN OF WAVE-ACTION MODELS}

The Indiana Harbor models were designed to investigate the effects on harbor structures of wave action resulting from storms which generate surface wind waves. Surface wind waves in nature are generated by the tractive force of wind over water, and are propagated by the restoring force of gravity. Model waves are also propagated by the restoring force of 
HYDRAULIC MODEL TESTS FOR INDIANA HARBOR DEVELOPMENT
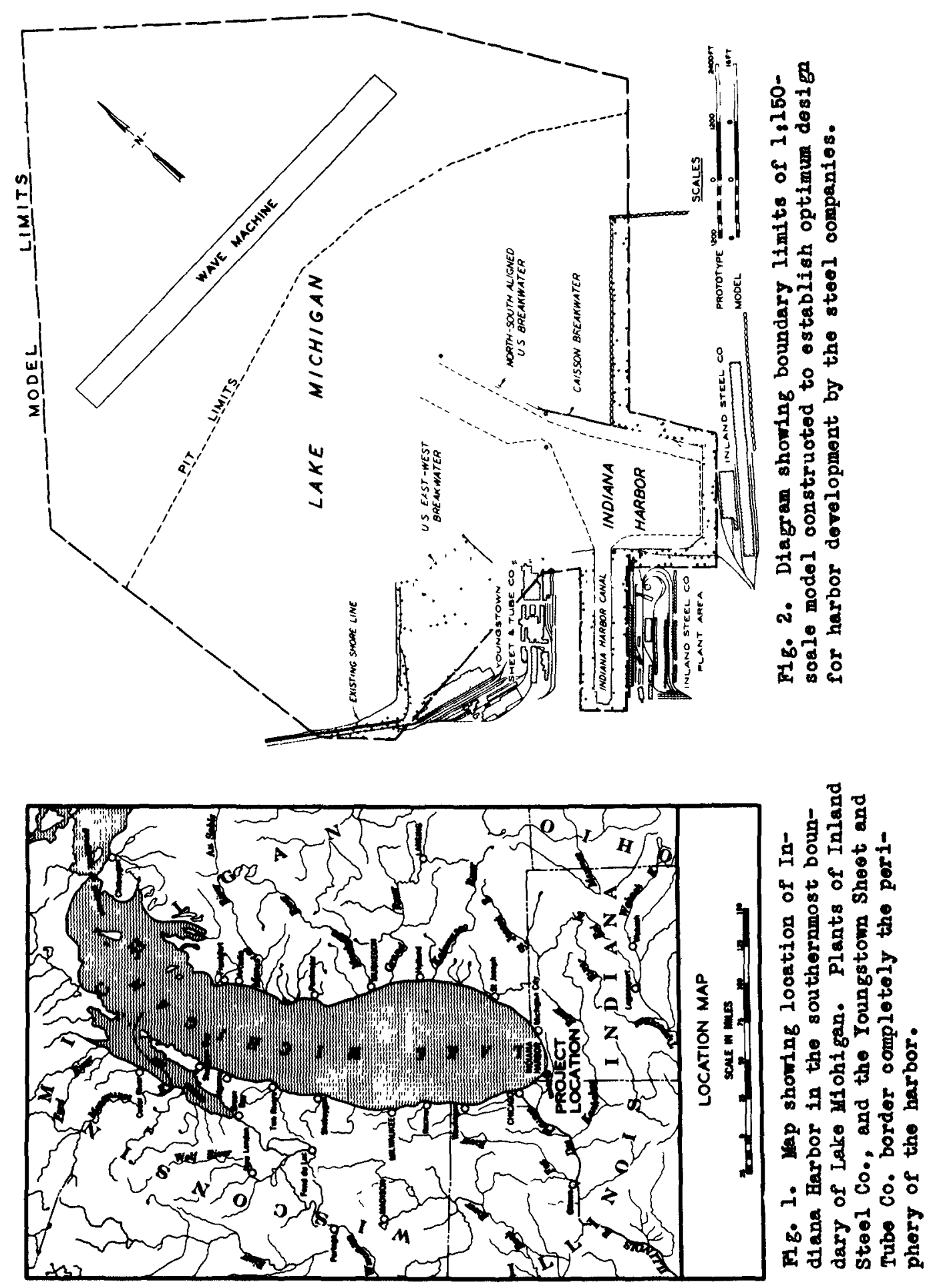


\section{COASTAL ENGINEERING}

gravity. However, in hydraulic models, the waves are generated by the displacement incident to vertical movements of a plunger in the water.

Economical considerations require selection of the smallest model consistent with the required accuracy of test results. If the model is too small, the forces of surface tension and friction may become sufficient in magnitude, relative to the force of gravity, to preclude accurate reproduction of wave phenomena. The type of instrumentation necessary, and the required degree of accuracy of test measurement, are also primary factors in selection of model scale. Thus, in the case of the Indiana Harbor model, where it was only necessary to obtain overall harbor wave heights and current patterns, a linear scale of 1:150, model to prototype, was selected. Fig. 2 shows the extent of the harbor and lake areas contained within the 1:I50-scale model limits. For the section models which involved measurement of wave forces, the absorption of wave energy and the stability of rock in the breakwaters and wave absorbers, linear scales of 1:50 and 1:55 were selected. The change in scale from $1: 50$ and $1: 55$ was for convenience of model operation only, and is not significant with respect to accuracy of results.

Both types of models were designed and operated in accordance with Froude's model law, and constructed geometrically similar to the prototype harbor and harbor structures to insure dynamic similarity of motion occurrences. The following scale relationships (model to prototype transference equations) were derived based on Froude's model law, a specific weight scale of $1: 1$, and linear scales of $1: 150,1: 55$, and $1: 50$ (Table 1 ).

TABLE 1

TABULATION OF MODEL TO PROTOTYPE SCALE REIATIONSHIPS FOR VARIOUS IENGTH RATIOS

Characteristic 1:150-Scale Model 1:55-Scale Model 1:50-Scale Model

$\begin{array}{llll}\text { Length } & 1: 150 & 1: 55 & 1: 50 \\ \text { Area } & 1: 22,500 & 1: 3025 & 1: 2500 \\ \text { Volume } & 1: 3,375,000 & 1: 166,375 & 1: 125,000 \\ \text { Time } & 1: 12.25 & 1: 7.42 & 1: 7.07 \\ \text { Velocity } & 1: 12.25 & 1: 7.42 & 1: 7.07 \\ \text { Unit Pressure } & 1: 150 & 1: 55 & 1: 50 \\ \text { Force } & 1: 3,375,000 & 1: 166,375 & 1: 125,000 \\ \text { Weight } & 1: 3,375,000 & 1: 166,375 & 1: 125,000\end{array}$

\section{SELECTION OF TEST-WAVE DIMENSIONS AND DIRECTIONS}

Judicious selection of test waves requires adequate data of wave-period spectrums and corresponding wave heights which occur at the harbor from different directions of approach. In many similar model studies it is necessary to know the frequency of occurrence of storm waves of different magnitudes from the different directions. However, in this instance, it was not necessary to determine frequency of occurrence of storm waves from the different 


\section{HYDRAULIC MODEL TESTS FOR INDIANA HARBOR DEVELOPMENT}

directions because the primary purpose of the study has such that the analysis of model test results could be made on a comparison basis. It was sufficient for purposes of this study to select test waves based on the estimated average storm waves from the different directions at Indiana IIarbor.

Wave dimensions in nature have never been recorded systematically as has been the case for storin winds. Surface water waves are the result of wind blowing over bodies of water, and the magnitude of 'waves is a function of wind speed, wind duration, and the fetch or distance over which the wind blows. The lack ot' adequate wave records made it necessary to estimate the characteristics of waves at Indiana Harbor from available wind data and theoretical and empirical wave charts and formulas. Available wind data consisted of a wind rose for the years 1932-1946, and a record of 13 severe storms. These data were furnished by the Chicago District, Corps of Engineers, Department of the Army.

After waves are generated by storms over deeper portions of the lake, they travel into shallow water where they "touch" bottom and are influenced in their travel toward shore by the pattern of bottom contours. Where the depth of water is considerably less than one-half the wave length, the direction of travel of wave fronts is affected by changes in depths of water. Thus, when waves approach shore at an ancle, the crests bend because the portion that is nearer shore is in shallower water and travels more slowly than the more off-shore portion. The bending of wave crests in this manner is called "refraction" because of its analogy, to the bending of light rays in optical systems. The results of refraction are changes in wave height and the direction of travel of wave crests. Depth contours can be such that they cause waves to be focused on a harbor, or a particular portion of a harbor structure. Also, depth contours can be such that large waves are both reduced in height and changed in direction to the extent that only the smaller waves reach the harbor from a particular deep-water storm direction. The hydrography lakeward of Indiana harbor is relatively shallow for a considerable distance. Therefore, the effects of wave refraction played an important role in the selection of model test waves.

The effects on waves of changes in depth contours are best determined graphically by wave-refraction diagrams. Before performing the Indiana harbor model studies, the deep-water wave dimensions were selected with the aid of Stevenson's formula ${ }^{2}$ and the Sverdrup-Munk curves, 3 which show quantitatively the relationship between wind speed, wind duration, fetch, wave heights, and wave periods. Shallow-water wave dimensions and directions, corresponding to selected deep-water wave characteristics, were estimated by charting the deep-water waves into shallow water, to the outer areas reproduced in the model, by refraction diagrams. 4 Wave heights, periods, and directions determined in this manner were generated in the model by wave machines. The depth contours in the harbor model between the wave machine and the harbor and harbor structures were reproduced accurately in concrete. Therefore, the effects on wave characteristics caused 


\section{COASTAL ENGINEERING}

by changes in depth, from deep water thence thrcuch shallow water to the harbor, were reproduced with considerable accuracy.

Table 2 slows the selected test waves in deep water and after refraction for the different storm directions $(E=$ wave heisht, $T=$ wave period):

\section{TABLE 2}

TABULATION OF CFARACTERISTIC WAVES ESTALIISIED FOR HYDRAUIIC MODEL SIUDIES OF INDIANA HAFBOR

Deep-Water Waves

\begin{tabular}{|c|c|c|c|c|c|}
\hline Direction & $\mathrm{H}(\mathrm{Ft})$ & $T(\operatorname{Sec})$ & Direction & II $(F t)$ & $\mathrm{T}(\mathrm{sec})$ \\
\hline 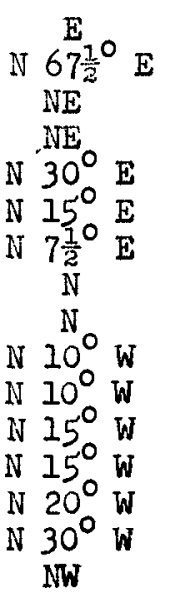 & $\begin{array}{c}5.5 \\
10.0 \\
13.0 \\
-- \\
-. \\
17.0 \\
17.0 \\
17.0 \\
-\overline{15.0} \\
=- \\
13.0 \\
=- \\
11.5 \\
7.0 \\
4.0\end{array}$ & $\begin{array}{l}3.5 \\
5.0 \\
6.0 \\
-- \\
-- \\
8.0 \\
8.0 \\
7.5 \\
-.- \\
6.5 \\
-.- \\
5.5 \\
-.0 \\
5.0 \\
3.8 \\
3.0\end{array}$ & 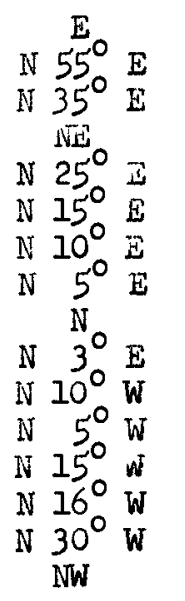 & $\begin{array}{r}5.0 \\
9.5 \\
9.0 \\
10.0 \\
15.0 \\
21.0 \\
16.0 \\
11.0 \\
9.0 \\
6.0 \\
8.0 \\
7.0 \\
7.5 \\
7.0 \\
6.0 \\
4.0\end{array}$ & $\begin{array}{l}4.0 \\
5.0 \\
4.0 \\
7.0 \\
8.0 \\
8.0 \\
7.5 \\
4.0 \\
6.5 \\
4.0 \\
5.5 \\
4.0 \\
4.0 \\
4.0 \\
4.0\end{array}$ \\
\hline \multicolumn{6}{|c|}{ * At position of wave machine } \\
\hline
\end{tabular}

In those instances where the selected shallow-water wave period in the above tabulation is less than the corresponding deep-water period, the wave height in shallow water corresponding to the smaller period is larger than that of the larger period. In those instances where the selected shallow-water period is greater than the corresponding deepwater period, the value of the deep-water period was so small that the RPM of the available wave machine was exceeded.

\section{OPERATION OF THE MODELS}

The 1:150-scale harbor model was first operated with conditions in the harbor reproducing those which existed prior to installation of problem structures under consideration. These initial investications are called "base tests." The purpose of base tests is to obtain basic data for use as a reference to which the results of tests of various proposed plans may be compared. Using selected test waves from the critical directions, wave heights, and current patterns were determined throughout the harbor and 


\section{HYDRAULIC MODEL TESTS FOR INDIANA HARBOR DEVELOPMENT}

in the navigation channel for base-test conditions and with the different proposed plans ipstalled. Wave heights in the model were measured with wave-height gages, ${ }^{5}$ or pick-up units, in connection with a recording oscillograph. A wave-height gage consists of series-connected resistors installed in $a$ direct-current circuit with the resistors so calculated that the current varies directly with submergence of the gage in water. Currents were determined by small pole-type floats.

The 1:50- and 1:55-scale section models were conscructed in existing wave flumes. The breakwater and wave-absorber sections were constructed in the flumes using crusined rock and molded concrete blocks to simulate the prototype core material and cap rock. The test sections were placed at one end of the flumes and waves were senerated at the other end. The stability of breakwater sections, the absorption and reflection characteristics of wave absorbers, and wave forces on a proposed vertical-wall parapet were determined in these tests. Wave forces on the parapet were recorded electrically with a pressure cell connected to a recordins oscillograph.

\section{SOLUTION OF INDIVIDUAL PROBLENS}

The elements of plans and changes in harbor boundary conditions for each problems studzed in the Indiana Harbor investigation are shown by Fig. 3. The following presents a brief description of each major problem, outlines the tests performed, and summarizes salient test results.

\section{YOUNGSTOWN SUEET AND TUBE CONPANY'S NORTHWEST BULKHEAD} (PROJECT AREA I, FIG. 3)

The Youngstown Sheet and Tube Company constructed a sheet steel pile, cellular bulkhead $2500 \mathrm{ft}$ long, west of the navigation channel and aligned in a northwest direction parallel with the shoreline. The area behind the bulkhead is to be filled and reclaimed for use in future plant development. Immediately after construction of this bulkhead was completed, ships captains began complaining of unusually difficult navigation conditions in the entrance channel, although waves in the vicinity had been comparatively small in magnitude. It was surmised that the sudden change in navigation conditions was caused by waves, which previously had expended their energy harmlessly on the beach, being reflected from the verticalwall bulkhead across the navigation channel. The reflected waves were thought to impinge on the north-south aligned breakwater and reflect back across the chennel, thus causing standing waves with resultant surging of the ships in a direction perpendicular to the navigation channel.

Tests were performed on the 1:150-scale harbor model using waves from several storm directions to determine which direction, if any, resulted in waves being reflected across the navigation channel. These tests were made (a) for base-test conditions with the northwest bulkhead omitted; (b) with the bulkhead installed as it was originally constructed; and (c) with a rubble-mound wave absorber installed along the bulkhead on the lake side. It was found that the northwest bulkhead reflected waves 


\section{COASTAL ENGINEERING}

across the navigation channel sufficiently to cause adverse navigation conditions, and that the remedy consisted in placing a rubble wave absorber along the lakeside of the bulkhead. The optimum design of a stable waveabsorber section was determined by model tests on the 1:50-scale section model.

\section{DESIGN OF NORTHWEST BULKHEAD WAVE ABSORBER (PROJECT AREA I, FIG. 3)}

Tests on the 1:150-scale harbor model showed that a mubble wave absorber along the northwest bulkhead would prevent waves being reflected from the bulkhead into the navigation channel. Yowever, the 1:150-scale model was too small in size to allow determination of the optimum design of the wave absorber. It was desired to determine the smallest quantity of rock which would absorb sufficient incident-wave energy to reduce reflected wave heights satisfactorily.

Wave-absorber sections using different quantities of rock were tested on the 1:50-scale section model. Three sizes of prototype rock were simulated. The rock sizes tested were 1-4 ton, 3-10 ton, and 7-20 ton. Prototype rock of these weights were available locally in adequate quantities. The volume of rock in each wave-absorber section was determined by the berm height and width and slope of the rubble mound. The side slopes used to insure stability of the rock during wave attack were calculated using the generalized Iribarren formula, ${ }^{6}$ and coefficients established in previous model tests conducted at the Waterways Experiment Station. The efficiency of each wave-absorber section was determined as a function of rock size and volume by measuring the incident and reflected wave heights. Elements of typical wave-absorber sections (1-4 ton rock only) are shown on Fig. 5. Fig. 6 shows the per cent of incident wave energy absorbed as a function of volume of wave absorber and rock size. Based upon the results of these tests, a wave-absorber section having from 30-40 cu yd of rock per $f t$ was recommended. The rubble mound has now been placed in the field along this bulkhead and has eliminated the wave problem in the navigation channel.

\section{INLLAND STEEL COMPANY'S TIN-MILL DOCK (PROJECT AREA IV, FIG. 3)}

The Inland Steel Company's realigned tin-mill dock, located in the southeast corner of the harbor, was tested to determine whether realignment of the dock increased wave-action conditions in the harbor. Waveheight and current-pattern tests were performed on the 1:150-scale harbor model, with and without the realigned dock installed in the harbor, and it was determined that the realigned dock had no measurable effect on waveaction conditions in the harbor.

\section{YOUNGSTUWN SHEET AND TUBE COMPANY'S PIER EXPANSION} (PROJECT AREA II, FIG. 3)

The Youngstown Sheet and Tube Company plans to increase their plant area to facilitate railway materials handling by constructing a bulkhead 

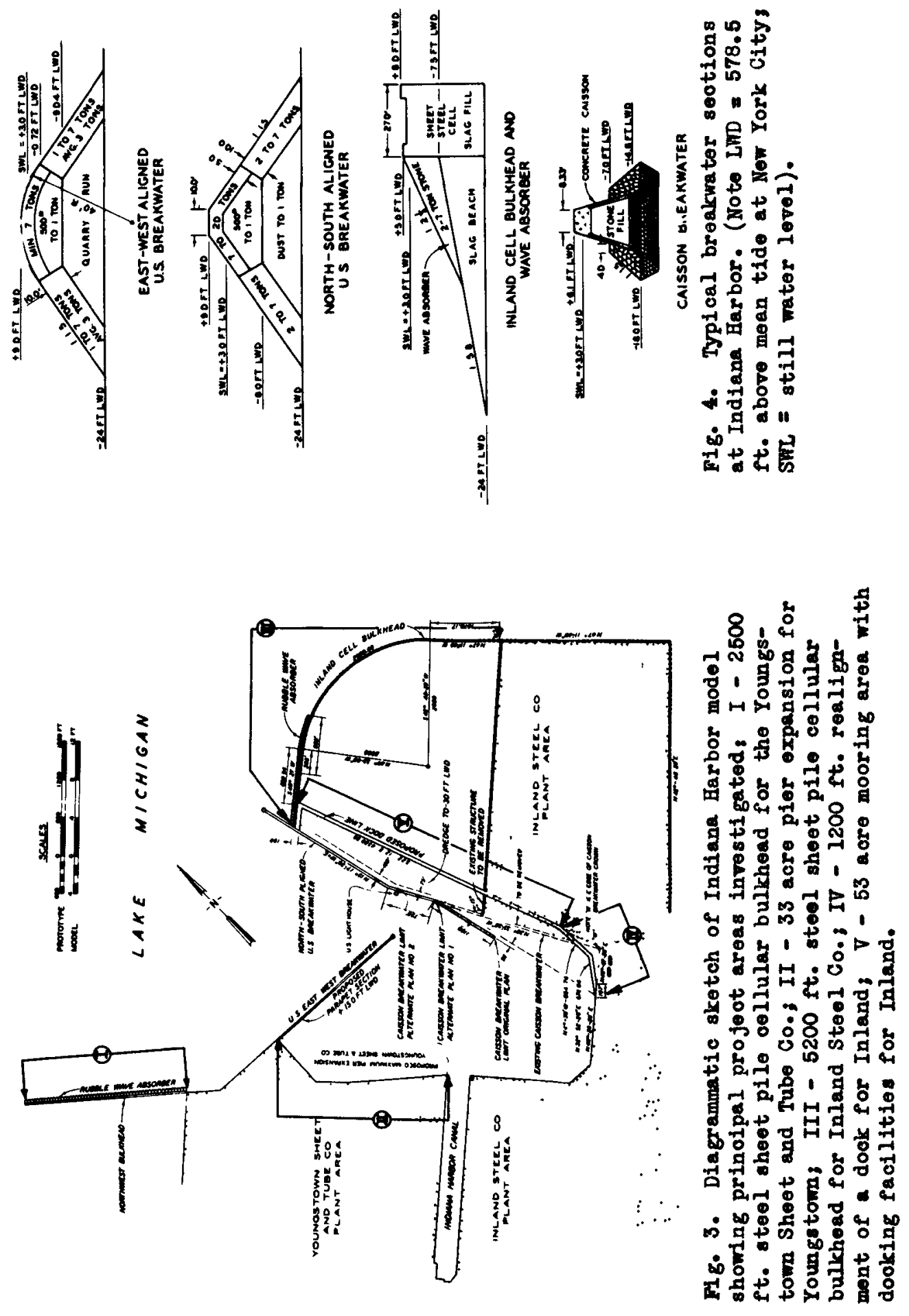


\section{COASTAL ENGINEERING}

in the northwest portion of the harbor, and again it was desired to determine whether this installation increased wave action inside the harbor. Wave-height and current-pattern tests were conducted with base-test conditions, and with the proposed plan of pier expansion installed in the harbor. It was found that while installation of the pier did somewhat increase wave action inslde the harbor, various means of remedying the situation can be established. Tests were conducted which showed that the bulkhead could be constructed in the harbor without increasing wave action if a rubble wave absorber were installed along the bulkhead. However, with a view toward economy and also the potential desirability of using the bulkhead as a mooring dock for ships, which precluded the placing of a rubble mound along the pier, other means of rectifying the wave action have been explored. Tests were conducted to determine the minimum length of parapet on the east-west aligned U. S. breakwater required to reduce overtopping of storm waves sufficiently to allow construction of the bulkhead without an increase in wave action in the harbor. Results of these tests showed that the status quo with respect to wave conditions in the harbor could be maintained if overtopping were reduced to a satisfactory minimum along the western 1200 feet of the east-west aligned U. S. breakwater. The problem was then reduced to that of designing a revised section of the eastwest breakwater which would fulfill the minimum requirements of the permit at a minimum cost. A series of model tests on the 1:55-scale flume model was conducted to determine the required design section of (a) a rubblemound addition lakeward to the breakwater; (b) a concrete parapet surmountinE the breakwater; and (c) a sheet-steel pile wall inside the breakwater.

\section{INLAND STEEL COMPANY'S NORTHEAST BULKHEAD \\ (PROJECT AREA III, FIG. 3)}

The Inland Steel Company constructed a sheet steel pile, cellular bulkhead $5200 \mathrm{ft}$ long, east of the north-south aligned U. S. breakwater and north of their existing plant area. The area behind the bulkhead is to be filled and reclaimed for use in future plant development. A portion of the bulkhead perimeter reflected waves across the navigation channel. It was desired to determine by model tests the length of bulkhead which reflected waves across the channel, and the minimum volume of rock required to construct a wave absorber adequate to reduce wave reflection to a satisfactory minimum. The problem was similar to the northwest bulkhead problem, except that the Inland Steel bulkhead was curved convex to the waves. This convexity limited the leneth of bulkhead which could reflect waves across the channel. Also, the Inland Steel bulkhead was provided considerable protection by the installation of an underwater slag fill shortly after the bulkhead was constructed. Another problem requiring solution was that of waves reflecting from the bulkhead and impinging directly onto the north end of the north-south aligned U. S. breakwater. It was feared that these waves, which were larger than those which had attacked the breakwater prior to construction of the bulkhead, would endanger the stability of the breakwater.

Tests were conducted on the 1:150-scale model to determine which portion of the Inland Steel bulkhead reflected waves across the navigation channel. Tests were conducted on the 1:50- and 1:55-scale models to 


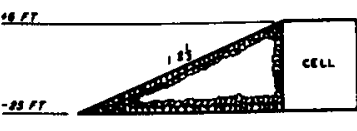

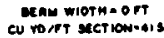

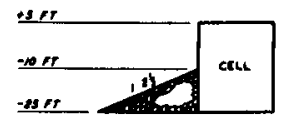

ceav mosk - a pt

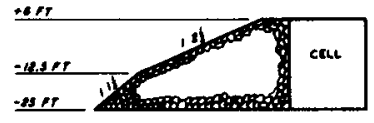

exhu woth - 10rT
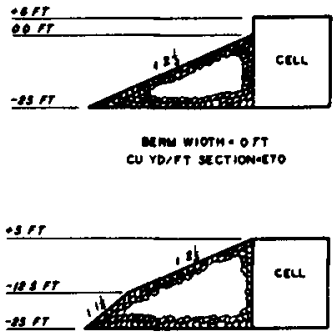

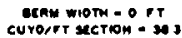

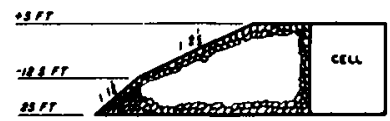

Ccem wOTh - 2007

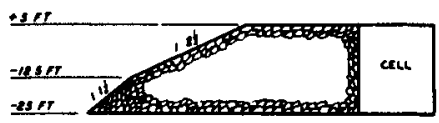

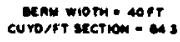

Fig. 5. Diagrammatio seotlons showing typioal wave absorbers tested in 1,60-8oale model to establish optimm design for absorbing waves otherwise refleoted from northwest bulkhead aoross narigation ohannel. All tests in this series of experiments simulated to 1 to 4 ton rooks the elevations are reforred to low water datum on Lake Miahigan.

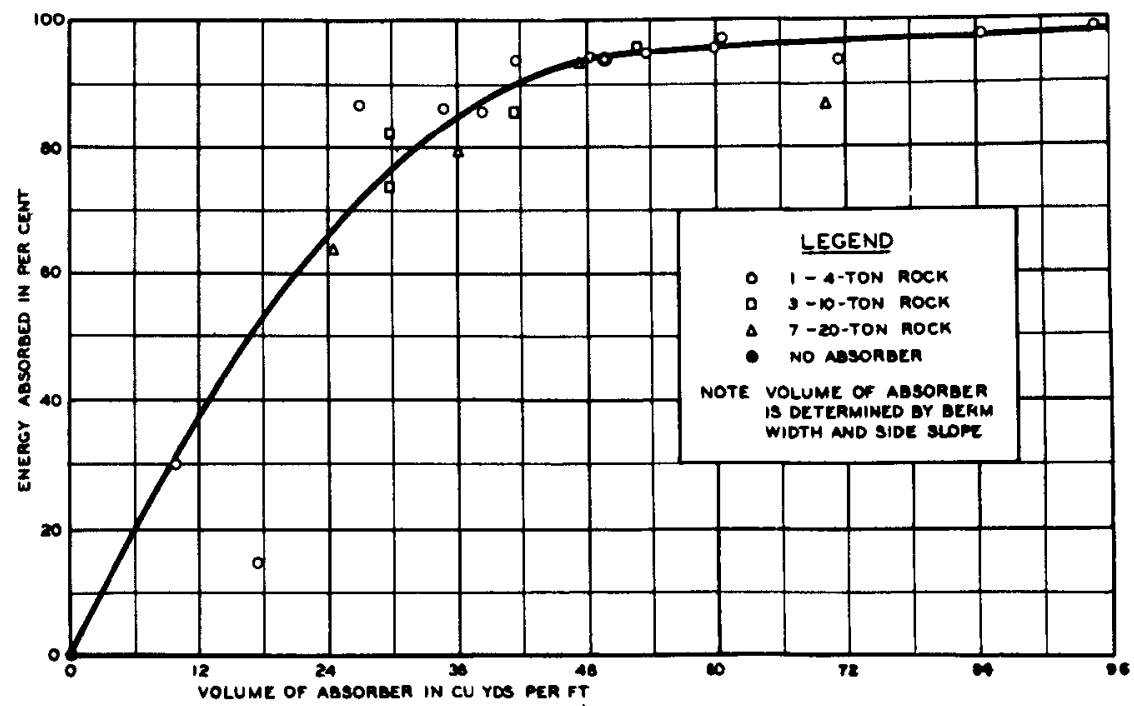

Hg. 6. Results of experimental study of efflolenoy of wave absorbers for northrest bulkhead. Experiments conducted on 1,50-soale model. 


\section{COASTAL ENGINEERING}

determine the minimum amount of rock necessary to provide an adequate wave absorber, and the effects of reflected waves on the stability of the adjacent U. S. breakwater. It was found that a 900-ft reach of the bulkhead perimeter reflected waves across critical reaches of the navigation channel. The minimum design section of the combined slag-rock fill devised to absorb incident wave energy sufficiently to provide adequate protection to the navigation channel from reflected waves is shown by Fig. 4, 3rd section. The results of the stability tests of the adjacent north-south aligned breakwater with and without an added wave absorber in the corner, formed by the breakwater and bulkhead, are very significants the reflected waves from the bulkhead without the added wave absorber did considerable damage to the breakwater. After the wave-absorber section was extended from the west end of the $900 \mathrm{mt}$ absorber to the corner, the reflected wave energy was not sufficient to endanger the stability of the breakwater. Construction of a rubble wave absorber from the west end of the 900-ft absorber to the corner was established as an optimum solution.

\section{TNLAND STEEL COMPAIV'S PROPOSED INNER-HARBOR SLIP AND DOCK (PROJECT AREA V, FIG. 3)}

The Inland Steel Company took advantage of the existing harbor model to test the effects on harbor wave action of a proposed layout for an inner-harbor slip and docking area envisioned in possible plans for future harbor and plant development. Tests were also desired to determine whether the protecting breakwater proposed for the slip entrance was necessary to provide adecuate protection to the slip. Wave-height and current tests were conducted with and without the slip installed in the model, and with various lengths of the originally proposed protecting breakwater at the entrance to the slip. Wave-action conditions in the slip were found to be satisfactory for all conditions tested. Test results also showed that the 1100-ft breakwater at the slip entrance could be eliminated without increasing wave conditions in the slip. The breakwater was also found to reflect waves across the harbor onto the proposed Youngstown Sheet and Tube Company piers. Therefore, both in the interest of economy and better navigation conditions, construction of this inner-harbor breakwater is not recommended.

\section{CONCLUSTONS}

The use of hydraulic models as a tool of the design engineer is feasible in many types of engineering projects. Where the problems of design have to do with the effects of wave action on harbors and harbor works, or where it is necessary to determine the effects of changes in harbor boundary conditions, resulting from a proposed harbor-development project, it is not only feasible but, in many instances, quite essential to conduct model studies if optimum designs are obtained. The complexity of wave-action phenomena and the complicated geometry of most harbors usually make it impossible to obtain adequate answers to problems of design by a purely analytical approach. The general experience and judgment of the engineer cannot be utilized effectively except for the most elementary wave-action problems. Indeed, this method of approach has led to designs 


\section{HYDRAULIC MODEL TESTS FOR INDIANA HARBOR DEVELOPMENT}

which not only failed to reduce wave-action conditions, but instead, actually intensified them. Therefore, the hydraulic model technique of such problems becomes indispensable to insure that the safest, most effective, and most economical harbor and breakwater design is obtained.

The Indiana Harbor model investigation is an excellent example of the value of model studies in providing design engineers and planning experts answers to difficult wave action problems pertaining to harbor and plant development. Results of the model tests provided direct and accurate answers to problems of harbor ccnstruction involving the expenditure of several millions of dollars. The cost of the model studies was within about one per cent or less of the estinated total construction costs.

\section{ACKNOWLEDGMENTS}

Of the two authors of this paper, Dr. Straub acted in the capacity of engineering consultant to both the Inland Steel Company and the Young6town Sheet and Tube Company in correlating results of the model tests and with the overall planning for the plant expansion. The model studies were conducted under the direct supervision of $\mathrm{Nr}$. Hudson. The engineering program of Inland Steel Company was under Fred H. Johnson, Chief Hingineer; Tom Pyhre, Plannine Engineer; and James Howard, Assistant Chief Engineer; for Youngstown Sheet and Tube Company it was A. J. Hulse, Chief Englneer. The hydraulic model studies were conducted at the Waterways Experiment Station of the Corps of Engineers.

\section{BIBLIOGRAPHY}

${ }^{1}$ ASCE, Manual of Engineering Practice--No. 25, Hydraulic Models, July $1942, \mathrm{p} .9$.

2 STEVENSON, Thomas, The Design and Construction of Harbors: A Treatise on Maritime Engineering. 3rd ed. Edinburgh, Adams and Charles Black, 1886, p. 29.

${ }^{3}$ SVERDRUP, H. V. and MUNK, W. H., Wind, Sea and Swell: Theory of Relations for Forecasting. Hydrographic Office, U. S. Navy Dept., H. O. Pub. No. 601, Washington, D. C., March 1947.

${ }_{4}$ SIO, Revised Wave Forecasting Graphs and Procedures. Scripps Institution of Oceanography Wave Report No. 73, La JoIla, Calif., University of California, March 1948.

5 For detailed descriptions see WES TM No. 2-237, Model Study of Wave and Surge Action, Terminal Island, San Pedro, Calif., dated September 1947, p. 24 .

6 Wave Forces on Breakwaters, by Robert $Y$. Hudson. Transactions, ASCE, vol. 118, pp. 653-674. 